\title{
Effect of RF-PECVD Synthesis Conditions on the Carbon Nanotube Growth
}

\author{
T. Jutarosaga, ${ }^{*}$ S. Seraphin, ${ }^{*}$ S. M. Smith, ${ }^{* *}$ and Y. Wei ${ }^{* *}$ \\ * Department of Materials Science and Engineering, University of Arizona, Tucson, AZ 85721 \\ ** Embedded System Research Lab, Motorola Inc., Tempe, AZ 85284
}

Carbon nanotubes (CNTs) have attracted much attention since their first discovery due to their mechanical and electronic properties such as high mechanical strength and high electron emission efficiency [1-3]. Especially, the vertically aligned CNTs for field emission display application are among one of the most interesting topics. It has been reported that various techniques including arc discharge, laser ablation, and chemical vapor deposition (CVD), can be used to grow CNTs [4-6]. Radio frequency plasma enhanced chemical vapor deposition (RF-PECVD) process has advantages over other methods because it operates at relatively low temperatures and can deposits on large area. However, the CNTs obtained from the RF-PECVD are not well aligned and contain very defective graphitic structures. In addition, there is a layer of carbon soot deposited on the CNTs. This study aims to improve the quality of aligned CNTs by investigating the relationship between the synthesis conditions (such as the gas chemistry and the temperature) and structures and properties of the CNTs.

The 2-nm NiFe layer, sputtered from an alloy target consisting of $80 \% \mathrm{Ni}$ and $20 \% \mathrm{Fe}$, was used as a catalyst for CNT growth. Then, the CNTs were synthesized by an RF-PECVD process. The R.F. power of $1.5 \mathrm{~kW}$ was applied to the gas-dispersion electrode (showerhead), whereas the substrate was placed on an earth ground heated electrode. The RF-PECVD system is described in detail elsewhere [7]. The mixture of acetylene $\left(\mathrm{C}_{2} \mathrm{H}_{2}\right)$ and ammonia $\left(\mathrm{NH}_{3}\right)$ with $\mathrm{C}_{2} \mathrm{H}_{2}: \mathrm{NH}_{3}$ ratio of 1:2 was used. The substrate temperature was varied from $350{ }^{\circ} \mathrm{C}$ to $440^{\circ} \mathrm{C}$. Scanning electron microscopy (SEM) and transmission electron microscopy (TEM) were used to investigate the structures of the CNTs.

Fig. 1 shows SEM micrographs of the CNTs synthesized at $350{ }^{\circ} \mathrm{C}, 400{ }^{\circ} \mathrm{C}$, and $440{ }^{\circ} \mathrm{C}$ on the silicon substrate. The images show significant effect of temperature on the structures of the CNTs. At 350 ${ }^{\circ} \mathrm{C}$, a film of amorphous carbon was formed without any CNTs. At $400{ }^{\circ} \mathrm{C}$, the CNTs were observed with the amorphous carbon film cover on top. At $440{ }^{\circ} \mathrm{C}$, the CNTs were formed with the length of about $300 \mathrm{~nm}$ and the top layer contains thinner amorphous film.

Fig. 2 shows TEM micrographs of (a) an overall structure and (b) a high-resolution of the CNTs synthesized at $400{ }^{\circ} \mathrm{C}$. Fig. 2 (a) reveals metal catalyst throughout the CNTs structure in areas closer to the substrate and in the amorphous-phase covered layers. Fig. 2(b) shows a tube with a metal catalyst particle at the tip. The tube was bamboo structure.

The above results show that higher substrate temperature enhances the growth of the CNTs due to the increase of the diffusion (both bulk and surface) of carbon through the metal particles, while the supplied species from the plasma $(\mathrm{C} 2, \mathrm{CH}, \mathrm{CN}$, and $\mathrm{H})$ are relatively unchanged. Attempts to grow CNTs with better alignment and to eliminate the top amorphous layer are under way. A better understanding on the growth mechanisms and a systematic control of the processing conditions on the CNTs structure and properties are needed in order to improve the quality of the CNTs. 


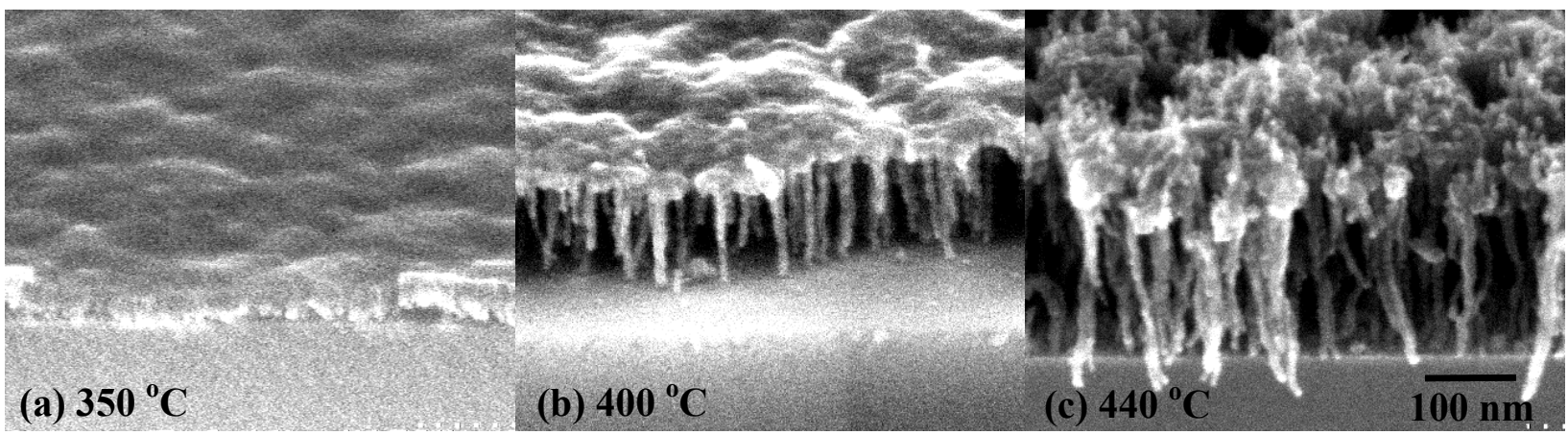

FIG. 1. SEM micrographs of CNTs synthesized at (a) $350{ }^{\circ} \mathrm{C}$, (b) $400{ }^{\circ} \mathrm{C}$, and (c) $440{ }^{\circ} \mathrm{C}$.

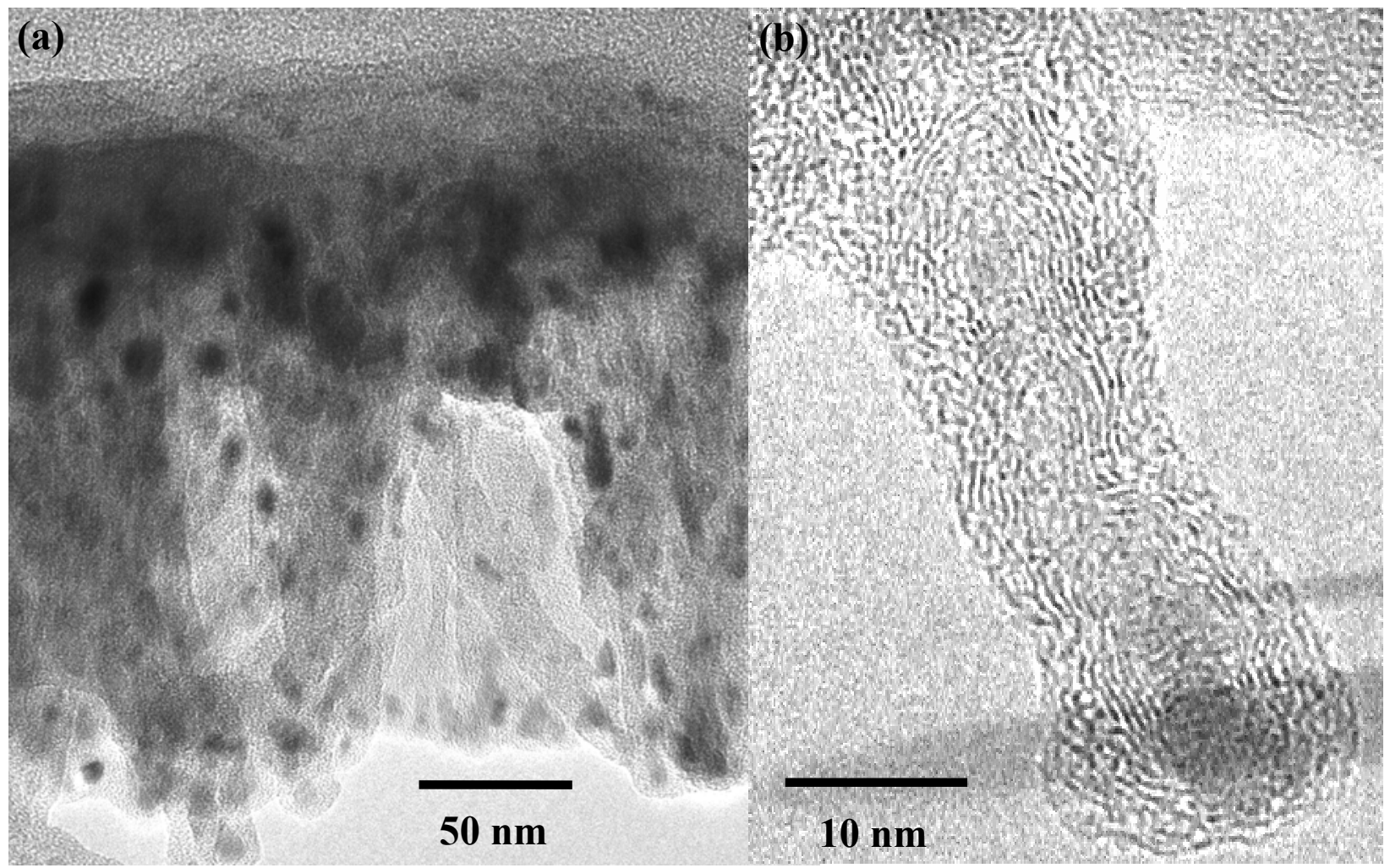

FIG. 2. TEM of CNTs synthesized at $400{ }^{\circ} \mathrm{C}$ : (a) an overview, (b) a high-resolution micrograph.

\section{References}

[1] S. Ijima, Nature, 354 (1991) 56.

[2] E.W. Wong et al., Science, 277 (1997) 1971.

[3] W.B. Choi et al., Appl. Phys. Lett. 75, (1999) 3129.

[4] T.W. Ebbesen and P.M. Ajayan, Nature, 358 (1992) 220.

[5] A. Thess et al., Science, 280 (1996) 483.

[6] J. Kong et al., Chem. Phys. Lett., 292 (1998) 567.

[7] S.M. Smith et al., Thin Solid Films, 398-399 (2001) 163. 